\title{
Student-Centred Teaching in Laboratories Supported with Online Components in the Orientation Program MINT ${ }^{\text {gruen }}$
}

\author{
By Franz-Josef Schmitt ${ }^{*}$ \\ Christian Schröder \\ Züleyha Yenice Campbell \\ Marcus Moldenhauer ${ }^{+}$ \\ Thomas Friedrich
}

\begin{abstract}
Research-based learning motivates students to identify with different subjects. The orientation program MINTgrün at Technische Universität Berlin offers two study semesters for open choices of teaching modules, including a series of specially designed laboratories covering topics like robotics, construction, environmental research, programming, mathematics, gender studies and chemistry. MINTgrün is open for students of any interest. The online project laboratory in chemistry (OPLChem) is one example of the MINTgrün labs. OPLChem follows the concept of research-based learning and allows for a free choice of an experiment drafted by the students themselves after participating in impulse talks that report on former experiments conducted by the students of the preceding semester. In the OPLChem, the students turned out to be highly motivated in choosing experiments of personal interest, which were often related to sustainability, such as decontamination of oil spills on water, production of biological plastics, quantification of heavy metals in tap water, comestibles and dietary supplements, investigation of electric bacteria, or the optimization of oxygen generation by algae, just to name a few examples. In addition, we developed a series of teaching videos for basic experiments in chemistry showing how to handle the experimental setups correctly. Such videos are identified as helpful tools to reduce the effort for supervision during the internships, while the quality of the experimental work of the students improves. The online materials offer important theory, show the chemicals, explain the preparation of samples and the configuration of complex setups, give safety instructions, and introduce programs for data evaluation. The concept of the OPLChem allows the students to produce their own videos as a support of their written protocols. In that way, a growing pool of new videos of various experiments is established and the students publish these videos, their protocols, and additional materials on their own blogs for the public.
\end{abstract}

Keywords: blended learning, MINT ${ }^{\text {gruen }}$, orientation studies, practical courses, research-based learning.

\footnotetext{
${ }^{*}$ Scientific Staff, Technical University of Berlin, Germany.

'Scientific Staff, Technical University of Berlin, Germany.

${ }^{*}$ Scientific Staff, Technical University of Berlin, Germany

${ }^{+}$Scientific Staff, Technical University of Berlin, Germany.

'Professor, Technical University of Berlin, Germany.
} 


\section{Introduction}

In the field of STEM studies (science, technology, engineering and mathematics) (in German: MINT (mathematics, informatics, nature sciences and technics)) students drop out from university early during their studies, if the demands of the different graduation courses are underestimated. The Bachelor of Chemistry at Technische Universität Berlin (TU Berlin) is actually facing a 50\% drop out ratio.

We infer that many students lack motivation in that initial stage of their studies, as their timetables are filled with mandatory subjects. In chemistry a large number of internships with clearly defined experiments have to be executed in short time spans.

Therefore, it seems reasonable to introduce orientation studies that help students to identify their personal interests and skills before choosing a defined graduation course. Orientation studies can reduce the number of drop out students and better provide a motivating and interactive start of the studies.

TU Berlin offers a special orientation program of two semesters (one year) called MINT $^{\text {grün }}$. The target group of MINT ${ }^{\text {grün }}$ are young students of any interest who have just left school. These students get an overview on the large number of STEM graduation courses and the basic demands in the corresponding subjects (Raue \& Schröder, 2014).

Orientation is one aspect of finding the right place in a large variety of possibilities. Another important aspect is the right motivation by interactive involvement of young students during lecture times and practical courses. The structures of some graduation courses present stringent sequence of frontal lectures in large groups with few possibilities for interaction. Therefore, there is a lack of student-centered learning environments offering interactive laboratories such as in MINT $^{\text {grün }}$. The students are free in choosing one specially designed laboratory covering topics like robotics, construction, environmental research, programming, mathematics, chemistry, hydrodynamics or gender studies. In the laboratories the students formulate their own research question which is often related to actual research topics in ecology, sustainability, or refers to social or intercultural debates of high societal interest (Schmitt et al., 2017a).

In the framework of MINT ${ }^{\text {grün }}$ we offered the Online Project Laboratory in Chemistry (OPLChem) which was developed 2013 as facultative module of the Bachelor in Chemistry curriculum. The OPLChem follows the concept of research-based learning (RBL) and allows for a free choice of an experiment, drafted by the students themselves after participating in impulse talks, that report on former experiments conducted by the students of the preceding semester or stimulating talks given by the instructors. These talks motivate the students to consider their own research question.

The students organize the conduction of their studies participating in an accompanying seminar. Besides positive effects of research-based learning as described in detail by Huber (2013), orientation is achieved by the experiences the students gain in the laboratories during the participation in MINT ${ }^{\text {grün }}$ (Rademacher \& Schröder, 2015). 
RBL offers a chance of learning by doing, which is often neglected in theoretically oriented teaching. Contents are experienced independently and creatively rather than abstractly and academically. In addition to the basic theory, the students can already get in touch with interesting topics in the early semesters instead of the later ones during their Bachelor's and Master's theses. The solely abstract and theoretical approach often screens students out, even if they are actually interested and competent enough to fit in (Huber, 2013; Rademacher \& Schröder, 2015). "This is often sensed as the main problem in STEM based degree programs. That's why we chose explorative learning as a main concept in the labs" (Rademacher \& Schröder, 2015).

\section{Literature Review}

In recent years, several universities developed orientation programs. The universities in Heidelberg, Marburg, Tübingen, Stuttgart, and Würzburg designed orientation programs for students coming from abroad connected with language teaching. There are orientation programs like $\mathrm{MINT}^{\text {grün }}$ at TU Berlin designed for students of any background, but mainly student beginners, especially targeting students who search for orientation before deciding which of the topics offered at university target their interests most. Many MINT ${ }^{\text {grün }}$ students are school absolvents that just entered university, aging 18 years or even younger (Raue \& Schröder, 2014; Born, 2015).

For these students, orientation programs have been established with different architectures. Some contain mainly modules that are part of the existing curricula of other graduation programs, which are especially marked as suitable for the orientation program, for example at the university in Bayreuth. Other universities solely offer modules that are especially designed for orientation studies as in Freiburg. The most popular programs connect both (existing and especially designed modules) as done at TU Berlin, BTU Cottbus-Senftenberg and TU München. These programs last for one year and give students insight into the existing STEM graduation programs.

As RBL is intended to mainly train skills such as the ability for the autonomous design of research plans, responsibility for the outcome of projects, self-dependency and self-esteem (Huber, 2013), the connection of orientation studies and RBL seems to be most promising to achieve identity, orientation and self-confidence among the students (Rademacher \& Schröder, 2015; Born, 2015).

RBL is not clearly defined. It is sometimes described as a 5 or 7 stage process. Here we refer to a description as a process represented by 8 steps: Most importantly, RBL should communicate the research process to students and bring students into a situation where all steps of the research process have to be conducted. These can be: 1) Identification and definition of a research problem;2) Formulation of a scientific question; 3) Collection of information; 4) Definition and description of methods used, 5) Design, and strategy for the research; 6) Conduction of the experiments; 7) Documentation of all results; and 8) Interpretation, reflection, presentation and discussion with others. If it is correctly 
done, RBL combines a variety of learning and teaching strategies in order to connect research and instruction. As RBL is time consuming and sometimes demands 1:1 supervision (one research assistant available for one student), which is not affordable, we recommend digital technologies to assist this important approach to university education (Ifenthaler \& Gosper, 2014).

One approach to implement new technologies into curricula is based on the idea of a flipped or inverted classroom in which there is a "flipping" of the distribution of homework and presence teaching in the classroom (Baker, 2000; Berrett, 2012; Bishop \& Verleger, 2012). Learning materials are studied as a preparation instead of homework after the lecture. During classroom time, interactive work in specially designed tutorials is used to answer open questions of the students. The flipped classroom represents more interactive teaching, leaving more time for RBL (Baker, 2000; Fulton, 2012; Bergmann \& Sams, 2012; Tucker, 2012). The basic idea of inverted classroom is not restricted to theoretical subjects, but it transforms the perception of instructive elements from the classroom to the preparation time at home. The time of the classroom presence is better used for real performance instead of perception of instruction. The implementation of instructional teaching videos into general higher educational teaching is understood as blended learning or online teaching (Bonk \& Graham, 2006; Garrison \& Vaughan, 2008).

According to Schultz, Duffield, Rasmussen and Wagemann (2014) flippedclass chemistry students performed better and even had a favorable perception of this approach. We decided to apply the approach of targeted inversion to the internships in chemistry at TU Berlin and to involve the students themselves with the generation of videos as a form of documentation of their experiments. As this approach is different from the flipped classroom concept of a lecture, we called it the approach of targeted inversion (Schmitt et al., 2015; Schmitt et al., 2017b).

A clear advantage of the flipped classroom when using teaching videos instead of a face-to-face introduction, instruction or lecture is the possibility to receive the instruction itself directly from the teacher (in form of a video) adapted to the learners speed with unlimited opportunity for repetitions. Another option is the possibility to interrupt and complete the instruction with additional materials that help to understand the topic. The instruction from the personal educator can be received in any free time on the smart phone. Most importantly, students that participate in the practical courses can iteratively check for the instructions while working with the experimental setup, and therefore, they can check for an explanation directly from the teaching video whenever they struggle in completing an experimental step. This approach reduced the need for interruptions and questions to the supervisors during the internships significantly (Schmitt et al., 2017b). Recent studies showed that the inverted classroom is prone to equal or better learning outcomes as compared to classical teaching methods (Holmes Tracy, Painter, Oestreich, \& Park, 2015; Linga \& Wang, 2014; Ally, 2004; Hudson \& Luska, 2013) in many fields such as mathematics (Love, Hodge, Grandgenett, \& Swifta, 2014; Schmitt et al., 2015), economics (Prashar, 2015) or internships in chemistry (Schmitt et al., 2017b).

Our main idea of the targeted inversion is to extract the optimal and/or most 
advantageous approach from the concept of blended learning and to leave disadvantageous elements of online teaching behind (Olapiriyakul \& Scher, 2006). Therefore, only selected teaching steps with a clear special focus are produced in form of online videos (targeted inversion).

In spite of the advantages of RBL, there are also some disadvantages mentioned in literature. Some students that come directly from school are not used to working without a permanent control (Huber, 2013). Therefore, a clear definition of homework and elements to be presented at the beginning of an experiment or at the end of the course is necessary to ensure a fulfilling engagement of all students.

Estimating and grading the students work is difficult within the laboratories. It is mainly suggested to grade the protocols, the presentations, and the general project results (Huber, 2013). As the students of MINT $^{\text {grün }}$ can transfer their achievements if they decide to continue studying in STEM based courses, there is need to make their work comparable. However, it is often stated that the grades the students receive are just partially expressive because most of the learning effects and achieved competencies, such as acting with upcoming problems, are not gradable at all. Grading RBL is therefore generally problematic (Huber, 2013; Rademacher \& Schröder, 2015).

The teaching concept of the OPLChem was awarded by the Joachim Herz foundation with a Fellowship for excellent teaching for Thomas Friedrich in 2013. One year later, in 2014, the targeted inversion of internships in chemistry and tutorials in economics (as part of a collaboration with the faculty of economics (IGT-educationTUB) was awarded by Joachim Herz foundation with a Fellowship for excellent teaching for Franz-Josef Schmitt. Both projects were possible due to additional support in the framework of a study reform project called educationZEN funded by Technische Universität Berlin for a time period of 4 years.

\section{Methodology}

The study program MINT ${ }^{\text {grün }}$ is designed for matriculated students. However students can not matriculate into the study program MINT ${ }^{\text {grün }}$ directly (there is no graduation program MINT $\left.^{\text {grün }}\right)$. The students who participate in MINT grün $^{\text {gin }}$ matriculate into the bachelor of physics. In such way the students who continue their studies after finishing MINT ${ }^{\text {griu }}$ have to change their subject if they do not want to continue with studies of physics.

The orientation program MINT ${ }^{\text {grün }}$ covers two semesters with an overall workload of 30 credit points per semester as usual for Bachelor studies. According to the European credit transfer system (ECTS), one credit point should measure 25-30 $\mathrm{h}$ of work and therefore the expected working time to complete 30 ECTS points ranges between 750 and $900 \mathrm{~h}$ which means that, deducing 3 weeks of complete holiday from 26 weeks of a semester term (23 weeks) 32-39 h/week should be invested into the studies.

The obligatory teaching matter of $\mathrm{MINT}^{\text {grün }}$ comprises a rather small amount 
of 6 credit points per semester distributed to two courses, the "Scientific Window" and the "Orientation Course" (See blue modules in Figure 1).

Figure 1. Structure of the two Semester Program of the Orientation Studies MINT $^{\text {grün }}$

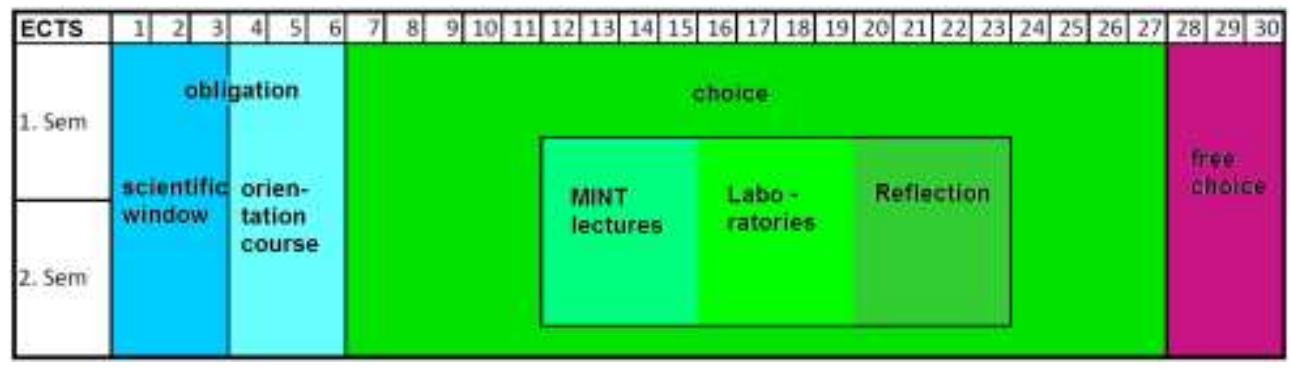

The facultative courses (choice) spread into four parts. The green modules (Figure 1) have to be chosen from three selected categories. These are 1) Regular lectures of the TU Berlin; 2) Laboratories; and 3) Courses from a specially defined reflection section. In total, 21 credit points should be covered during each semester within these three parts (green in Figure 1) of the facultative courses. The fourth part is of free choice, covering 3 credit points per semester (violet in Figure. 1). It can be chosen from any offered course of TU Berlin or any of Berlin's universities.

The Scientific window represents a rotating lecture where all faculties of TU Berlin contribute giving insights into their individual research and teaching topics. The module offers the advantage to interact with people studying, researching, and working in different academic fields to get an early insight into the academic reality.

The orientation module explains general organisation and content of university studies and operational training, and it explains differences in teaching structures.

Lectures (green section in Figure 1) can be chosen from any STEM lectures offered at TU Berlin. A seminar allows the students for reflection of their experiences to finally conduct the right decisions.

If the students have chosen and successfully conducted at least one module from each of the three fields: lectures, laboratories, and reflection (green part in Figure 1) and if they additionally successfully participated in the scientific window and orientation module (blue part in Figure 1), they achieve a certificate for their efforts in MINT ${ }^{\text {grün }}$. Next to that all achievements are registered and, in case the students proceed with any subject in STEM, they might claim recognition for their efforts previously obtained in MINT ${ }^{\text {grün }}$. Usually the subjects that fit into their chosen study programs are easily recognized and reduce their study time during the subsequent STEM based Bachelor studies. Possible recognition of further achievements is based on the regulations of the individual faculties that offer the study courses.

One additional element of MINT ${ }^{\text {grün }}$ is a series of social events. One of these events is a three-day workshop at the beginning of the program. During this workshop, the laboratories are presented and further elements of MINT ${ }^{\text {grün }}$ are 
explained to the new students. Also, elements of the university administration are introduced to the students. Social elements like open discussions or an evening barbecue help to come together and to share their expectations and knowledge with other students and teachers. Usually half of all students participate during that event. At the end of each semester, MINT ${ }^{\text {grün }}$ offers a competition where the students present their results obtained in the laboratories to their peers. These presentations are usually recognized as part of the laboratory achievements. Groups who do not actively participate during that competition event need to present their results to their peers during the laboratory time.

The Structure of the Online Project Laboratory in Chemistry (OPLChem)

Usually the students define their topics in the OPLChem within the first 2-3 weeks of the semester and come together in groups with ideally 4 participants. Large groups of more than 4 students should be divided into groups investigating subtopics to guarantee the engagement of all students into their project.

Figure 2 presents the structure of OPLChem in form of a Gantt chart. The semester is divided into three periods, which are marked with red lines on blue ground: 1) the introduction period, 2) the experimental period and 3) the presentation period. Marked with red lines on white ground (instead of blue) one can see the segmentation of the introduction period and the presentation period.

The introduction period mainly divides into i) the best practice examples introduced by students from former semesters or the instructors, ii) the investigation period for studying existing literature and collecting information, and iii) the conception period where all ideas are combined as an experimental concept, the methods are defined, the setup is considered, and the necessary materials are identified and organized.

During the experimental period, the students conduct their experiments in the laboratory. The presentation, which also contains the documentation, splits up into three segments: i) the web presentation usually as a Wordpress ${ }^{\circledR}$ blog, ii) the video production, iii) the protocol, and iv) the presentation (during the MINT ${ }^{\text {grün }}$ competition or in front of their peers at the end of the semester or the beginning of the next semester in form of a best practice example). The students are free in choosing to complete either a video, blog, or both (see results section). Together with the mandatory protocol and presentation these results are finally evaluated by the responsible supervisor.

The students are encouraged to discuss their results in a broad context. Such context might for example target sustainability questions or considerations of technical applications. For example, if students investigate electric bacteria the are encouraged to answer the question if electricity obtained from bacteria might significantly contribute to the world energy supply.

As the presentation and the best practice examples are connected, one can follow this connection from one semester to the next semester in Figure 2 (the following semester is marked with red squares on blue ground in Figure 2). All connections where results are transferred from one period into another are represented by dashed lines in Figure 2. 
Figure 2. Structure of the OPLChem

\begin{tabular}{|c|c|c|c|c|c|c|c|c|}
\hline & $\begin{array}{l}\text { Oct } \\
16\end{array}$ & $\begin{array}{l}\text { Nov } \\
16\end{array}$ & $\begin{array}{l}\text { Dez } \\
16\end{array}$ & $\begin{array}{l}\text { Jan } \\
17\end{array}$ & $\begin{array}{l}\text { Feb } \\
17\end{array}$ & $\begin{array}{l}\text { Mar } \\
17\end{array}$ & $\begin{array}{l}\text { Apr } \\
17\end{array}$ & $\begin{array}{l}\text { May } \\
17\end{array}$ \\
\hline \multicolumn{9}{|c|}{ 1. Introduction period } \\
\hline \multicolumn{9}{|c|}{ 1.1 Best practice examples } \\
\hline \multicolumn{9}{|l|}{1.2 Investigation } \\
\hline \multicolumn{9}{|l|}{1.3 Conception } \\
\hline \multicolumn{9}{|c|}{ 2. Experimental period } \\
\hline \multicolumn{9}{|c|}{ 3. Presentation period } \\
\hline \multicolumn{9}{|l|}{$3.1 \mathrm{Web}$} \\
\hline \multicolumn{9}{|l|}{3.2 Video } \\
\hline \multicolumn{9}{|l|}{ 3.3 Protocol } \\
\hline 3.4 Presentation & & & & & & & & \\
\hline
\end{tabular}

Instructive Online Videos. Teaching videos explaining basic setups that are available for a series of experiments in physical chemistry and organic chemistry support the teaching process.

We developed videos explaining how to handle the experimental setups like distillation, or chromatography or describing equipment like the evaporator or the fume hood ${ }^{1}$.

Further online materials explain important aspects of the theory, chemicals, the preparation of samples, the configuration of complex setups, safety instructions and handling of computer programs for the correct data evaluation ${ }^{2}$ (See Figure 3).

Sometimes it is believed that it might be difficult to apply the inverted classroom concept to practical courses, as such courses are already student centered. However, such general assumption is often based on the idea that the teaching environment of internships is inevitably bound to the university, and the structure of practical courses is fixed. During discussions with colleagues and students it turned out that the obligatory pre-examination, which was conducted before starting an experiment, was liked neither by students nor by teachers as it consumes a lot of the rare experimental time and has the image of an examination. Accordingly, in the framework of IGT-educationTUB, we produced online preexaminations that involve the teaching videos ${ }^{3}$ (See Figure 3 ). The online preexaminations mainly guarantee that the students have experienced the necessary skills in advance of the practical course to ensure their ability to conduct the experiments. The online pre-examinations contain a series of online tests (in form of alternative multiple choice tests) to check that the students have watched the videos, and are therefore prepared for the experiments (See Figure 4, right side). The great advantage of these online pretests is not only a fair and equal automated

\footnotetext{
${ }^{1}$ http://bit.ly/2AtxulB.

${ }^{2}$ http://bit.ly/2C3zw8S.

${ }^{3}$ http://bit.ly/2AaoqO1.
} 
self-assessment of the students' ability, but additionally the Moodle software allows for monitoring details of the study progress for each student (see Figure 4, left side), such as the time they finish the tests and the achievements obtained. In addition they reduce the supervision effort especially at the beginning of the experiment allowing for student-centered activities.

Figure 3. Example Screenshots of the Teaching Videos in Physical and Organic Chemistry
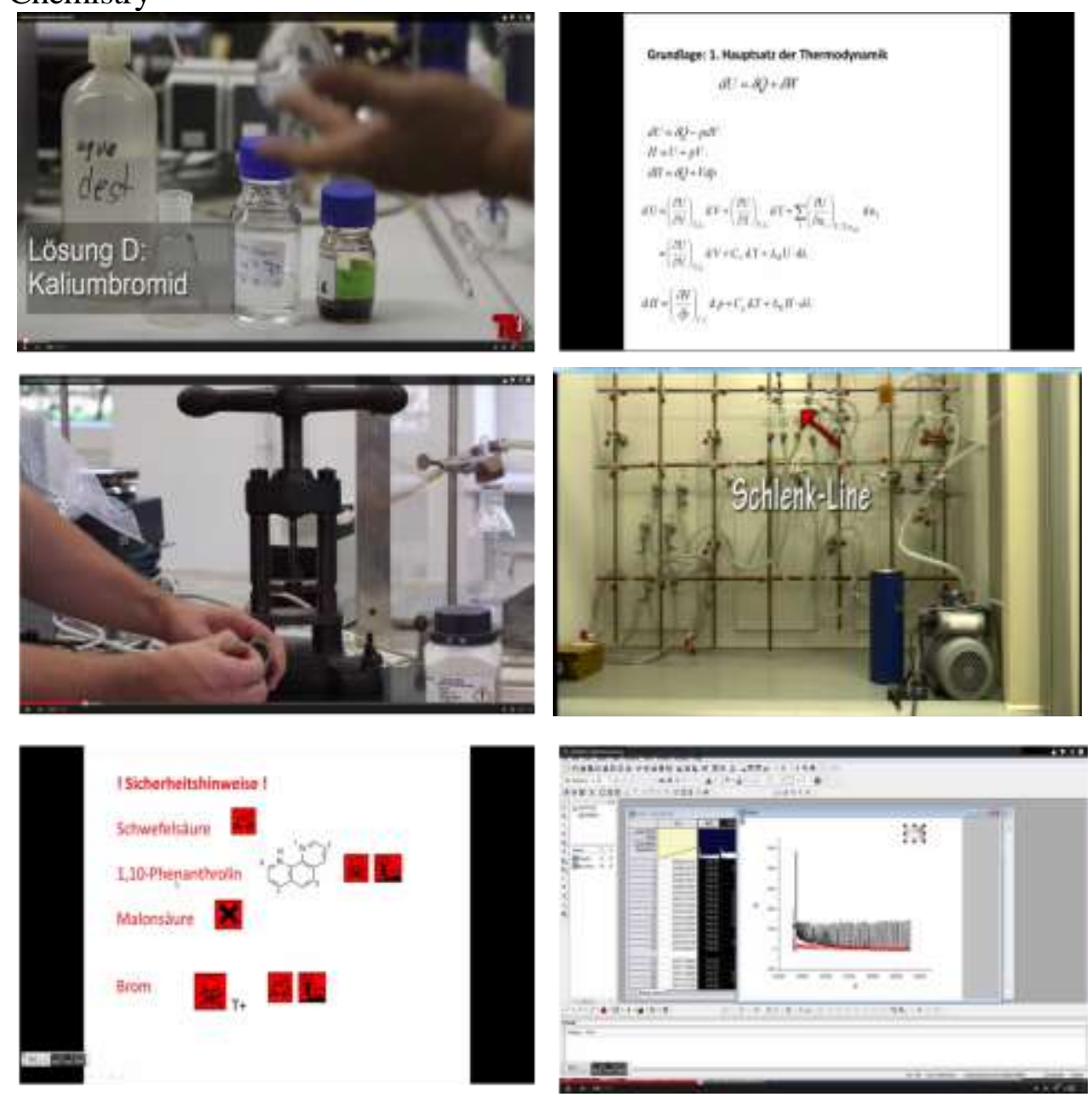

Figure 4. Student Performance (Left Side) and Online Pretest (Right Side)

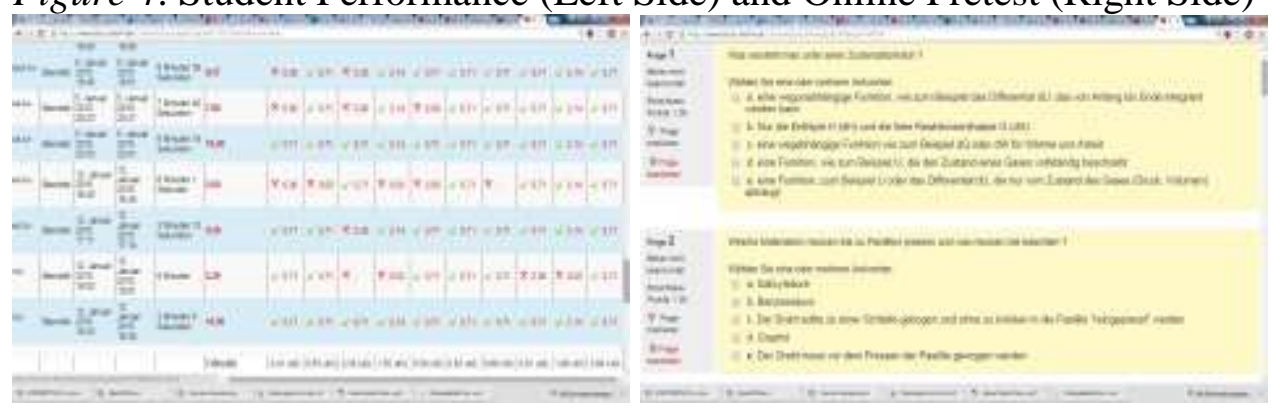


Figure 5. Screenshot of the Online Course OPLChem

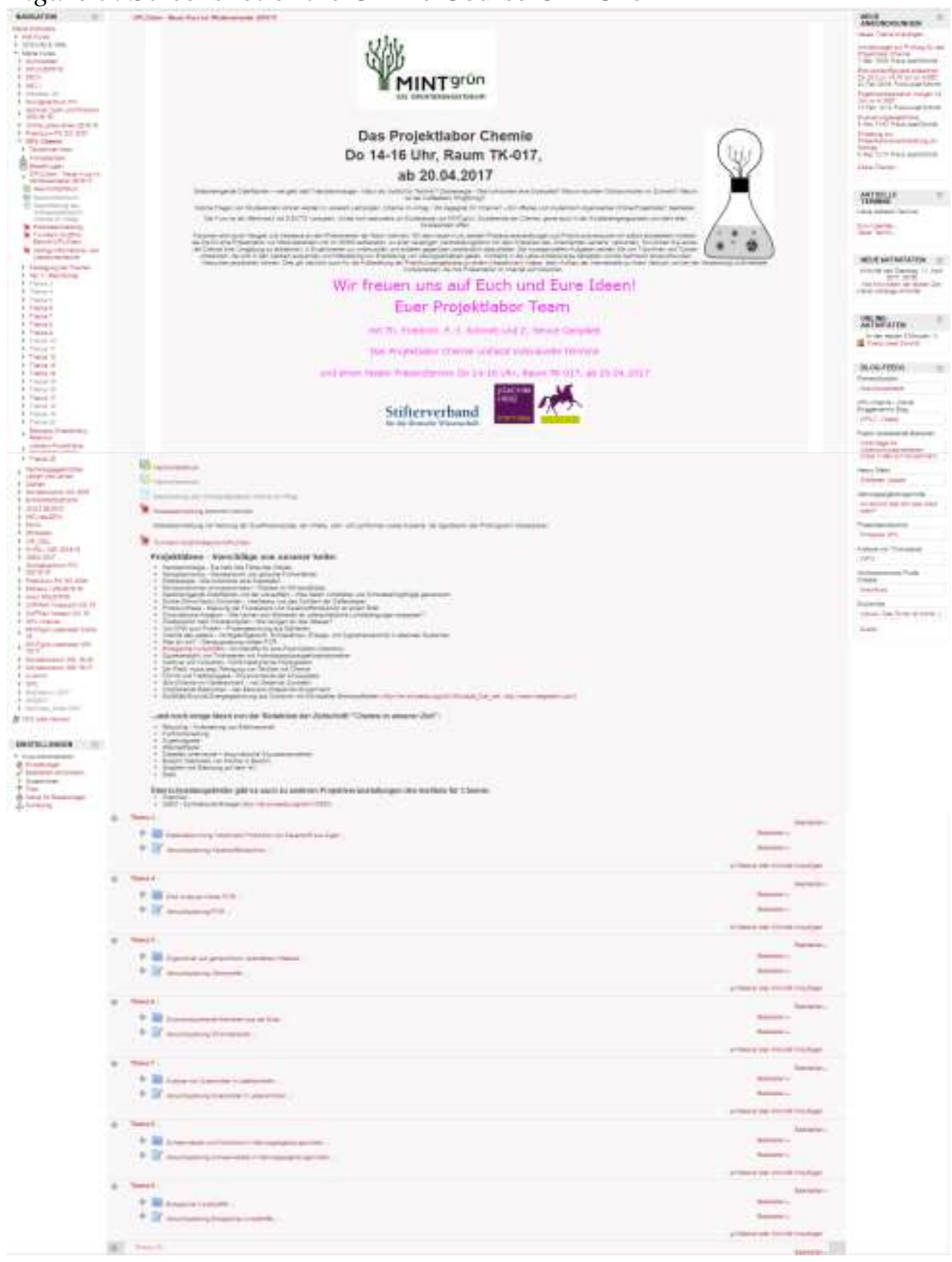

Online Plattform of the OPLChem. OPLChem is set up as an online course each semester before teaching begins. A web space on the Moodle-based content management system of TU Berlin is offered where the students organize the experiments of the OPLChem, meaning the assignment of students to the different experiments, collection of literature, links to the teaching videos and further online materials. Figure 5 shows a screen shot of the Moodle course of the OPLChem for the summer semester 2017, which includes the different student topics chosen during the winter semester 2016/17.

The online course not only allows for content management for each group, 
but also accelerates the decision process for the projects as discussions (forum) and voting tools and collaborative texting platforms are available.

Figure 6. Time Stamps of the Collaborative Etherpads of a student Group Investigating Nanoparticles

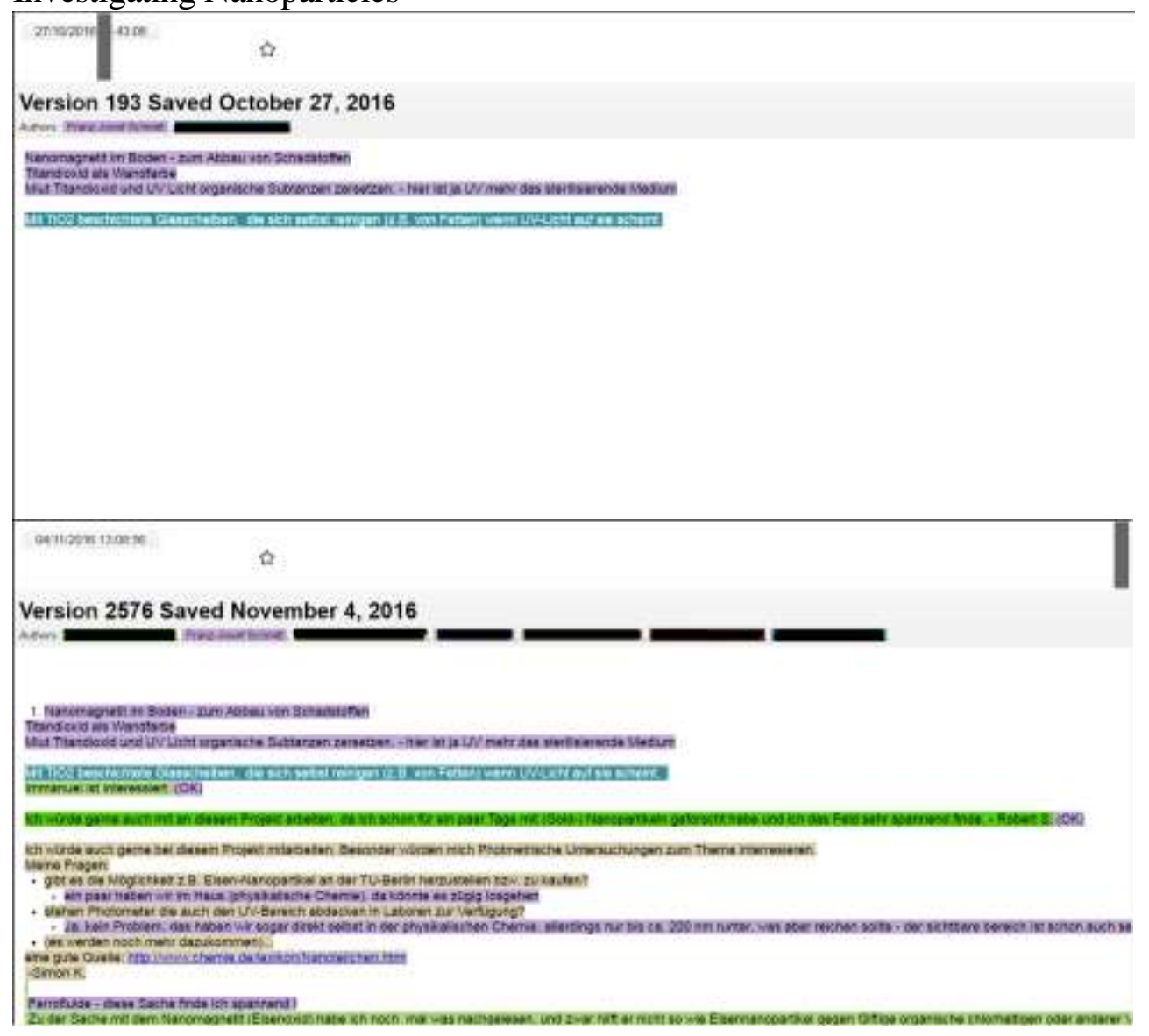

Especially collaborative working tools like etherpads are implemented and were found helpful. Each group gets an own etherpad allowing for the collaborative collection of information, comments and interaction by the students themselves. Etherpads are organized like a forum or wiki, but without the need for writing whole chapters or keeping an eye on the syntax. The structure is free and all changes are immediately visible for all participants and marked with a color that is characteristic for each author. Changes are automatically registered and saved. The time slider function can be used to show the temporal change of the pad during the semester, uncovering the contribution of each author by its individual color. The example of two time stamps of the etherpad used by the project group "generation and photocatalytic activity of nanoparticles" is shown in Figure 6. The upper panel shows the situation with only a few sentences presented by the instructor on October $27^{\text {th }} 2016$. The lower panel shows the situation one week later on November $4^{\text {th }} 2016$ (each color belongs to one student. For data privacy reasons, the names of the students are blackened). 


\section{Findings/Results}

During the last semester in winter 2016/17, 38 students participated in the OPLChem. They were supervised by one scientific assistant (Franz-Josef Schmitt) and one additional student tutor (Marcus Moldenhauer). The topics chosen by these students were: 1) oxygen production in photosynthesis, 2) light driven adaption of algae, 3) heavy metals in food supplements, 4) mercury in seafood, 5) gene analysis with polymerase chain reaction, 6) genetically modified organisms, 7) electricity produced by bacteria, 8) biopolymers, 9) generation and photocatalytic activity of nanoparticles, 10) function of ink erasers. In November 201721 students had completed the OPLChem (belonging to groups 1, 3, 7, 8, 9 and 10). It is expected that the remaining 17 students have decided not to finish the internship.

In recent years an average of about $50 \%$ of all students who had undergone the OPLChem finished. In that sense, these numbers are slightly better in the actual winter semester 2016/17. However the number of students who do not achieve to finish the OPLChem is still large, but in difference to subjects where the students fail to finish the final examination they decide actively if they feel able to finish their project in the OPLChem and are therefore much more autonomous.

\section{Student Blogs}

One part of the OPLChem is the production of videos and Wordpess® blogs presenting the project results. In that sense, a steadily growing pool of new videos of various experiments is established and some students published these videos, their protocols, and additional materials all together on their blogs for the public. This approach opened the laboratory to the public and turned out to be an interesting concept to support transdisciplinary and collaborations. For example, the project of one of the first groups investigating methods for oil spill detoxification in the summer semester 2014 was in focus of the public administration in Berlin. This finally led to cooperation with the office for urban development, which then supported student excursions to areas in Berlin where such oil spill detoxification is conducted.

Especially the students studying the Bachelor of Chemistry were strongly motivated by the concept of the OPLChem. Some of them expanded their projects to a larger extent than initially planned (see evaluation section).

All blogs as prepared by the students are collected in a metablog, which is accessible via the URL http://oplchem.wordpress.com. The screenshot of this blog is shown in Figure 7. 
Figure 7. Metablog Compiling the Students' Efforts in the OPLChem ${ }^{4}$

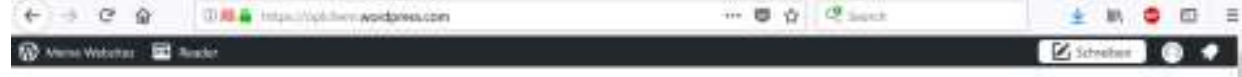

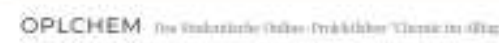
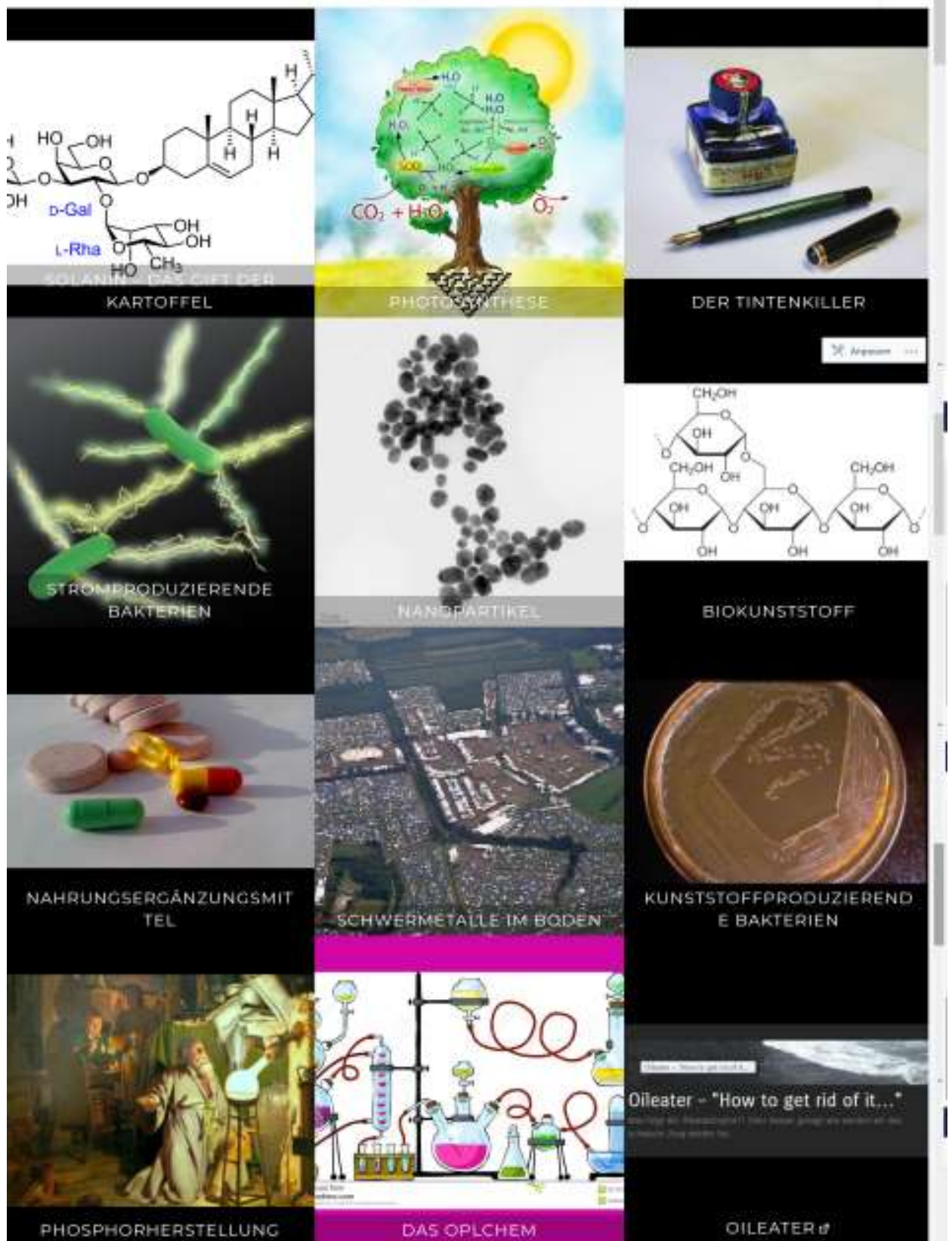

DAS OPLCHEM

OILEATER U
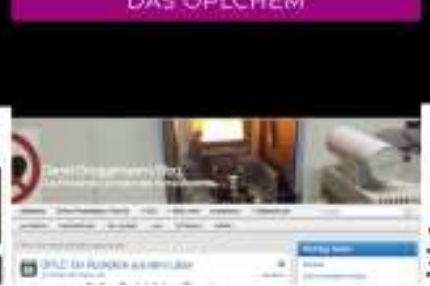

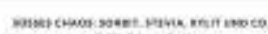

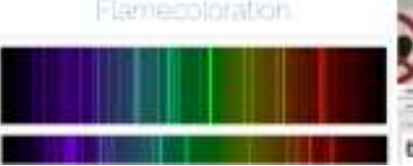

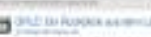

;

\footnotetext{
${ }^{4}$ http://oplchem.wordpress.com.
} 
Figure 8 presents a screenshot of one page of an example blog (biopolymers, group 8). The students synthesized a number of various biopolymers like polylactic acid, polyhydroxybutyrate, galalith and starch. They compared these polymers with industrial biopolymers, such as technically produced polylactic acid and synthetic polymers like polyurethane. The degradation in contact to earth and water, as well as the solubility in various different solvents, was studied. The findings were gathered in a protocol as well as structured as a presentation on the blog. For the synthesis of most of the biopolymers a short video was produced and linked to the blog. The students' presentation and discussion of their project covered about 1 hour, and the slides can also be found on the blog.

Figure 8. Screenshot of the Blog of a Student Group that Investigated Biopolymers in the Winter Semester 2016/17

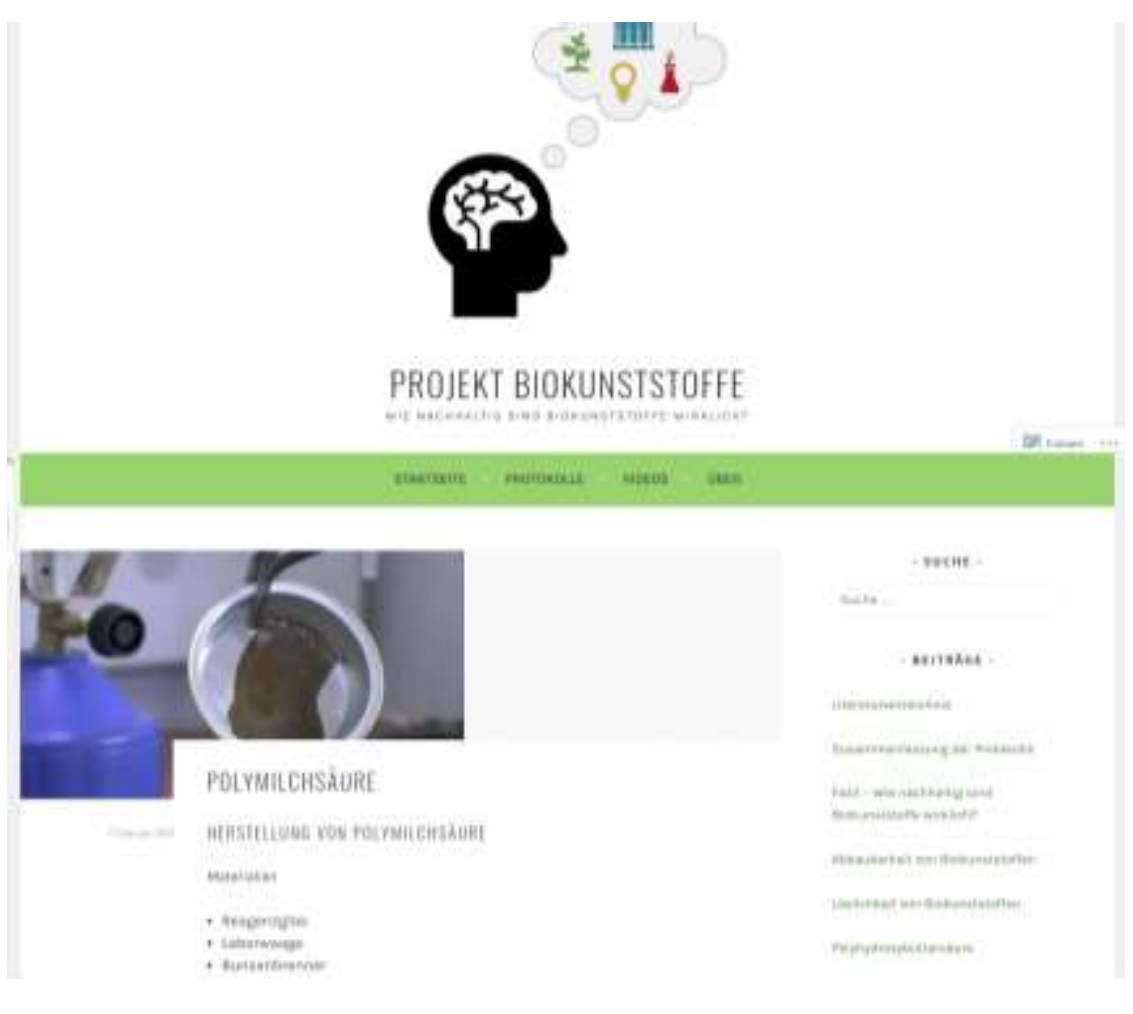

${ }^{5} \mathrm{http} / / / \mathrm{bit} .1 \mathrm{ly} / 2 \mathrm{kTjJWb}$ 


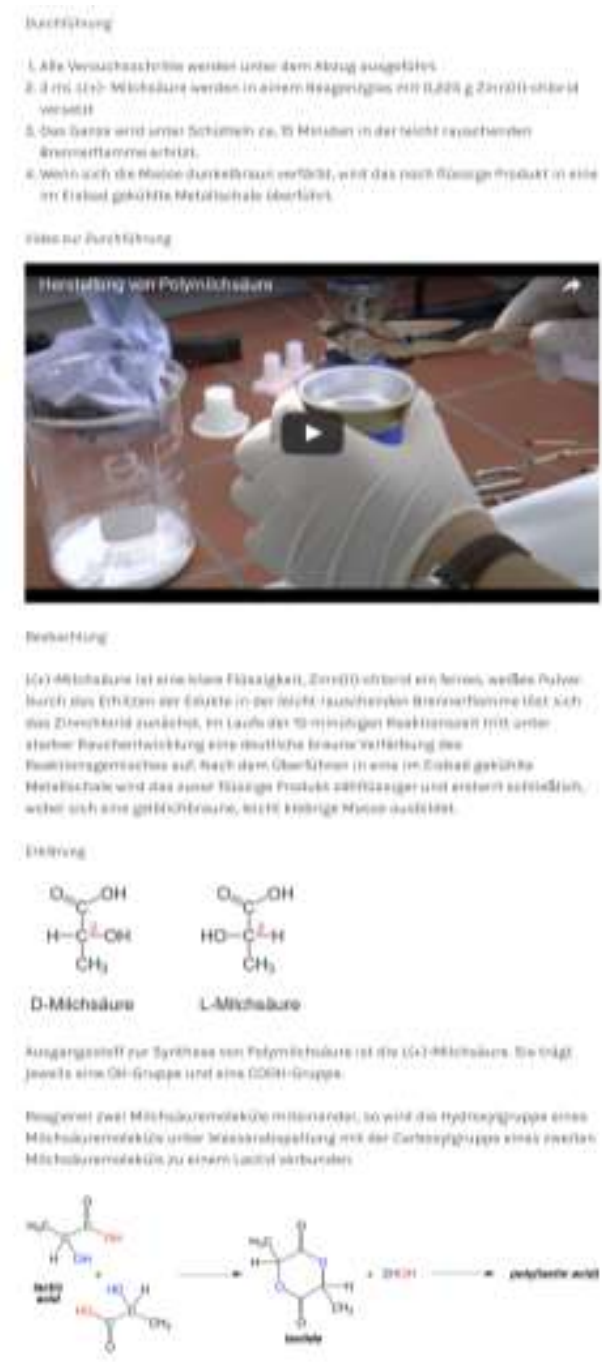

\section{Discussion}

The orientation study program MINT $^{\text {grün }}$ is very successful regarding the number of participating students. The number of MINT ${ }^{\text {grün }}$ students rose from 77 in the first year to 177 in the second year, 325 in the third year, and now around 500 students since 2015 . The amount of women grew from $22 \%$ to $34 \%$ in the same time. In the winter semester 2015/16, 21 students participated in the OPLChem and 38 students in the winter semester 2016/17. This number grew to more than the available capacity as 48 students participate now in the winter semester 2017/18. 34 students are from MINT ${ }^{\text {grün }}$ and 10 students from Bachelor of Chemistry. In addition 4 pupils from schools participate in the framework of school internships. 16 students in the OPL are women (33\%). About 1/3 of the students from MINT ${ }^{\text {griun }}$ in the OPLChem announced that they had interest in continuing with a Bachelor of Chemistry.

Generally, MINT ${ }^{\text {grün }}$ helped a lot of students to choose their future studies as $75 \%$ of the students who wanted to continue with studies after finishing MINT ${ }^{\text {grün }}$ 
announced that they want to study STEM (Rademacher and Schröder, 2015).

The study program MINT ${ }^{\text {griun }}$ is open for students of all subjects. They are matriculated into the bachelor of physics only for formal reason. The students typically decide to continue studies at TU Berlin (50\%) or at any other university or technical college in Germany $(25 \%)$. Some even decide to leave university for operational training $(25 \%)$. We believe that the students benefit from the study program MINT $^{\text {grün }}$ to orientate themselves for a career inside or outside university at an early stage. The subjects chosen during MINT ${ }^{\text {grün }}$ might only be of minor relevance as the main factor that contributes for orientation is the overview on the offered university courses. Such general benefit for the participants of MINT ${ }^{\text {grün }}$ also accounts for the students who chose OPLChem as it delivers a general view on practical courses during the Bachelor of Chemistry. But additionally students have to find their research question and learn to organize their own project and collaborate as a group to achieve the study goals. In that way OPLChem is an exemplary laboratory in MINT ${ }^{\text {grün }}$ and all students profit from participation independently from their graduation program chosen later.

Interestingly, in the OPLChem the students often chose experiments related to sustainability (Schmitt et al., 2017a). The concept of the OPLChem seems to motivate the students to follow their interests, and it also activates them as they later have to present their projects as videos or blogs on the internet. The online materials available on the students' blogs are another aspect of sustainability, as the students' results are more persistently visible in comparison to the written paper protocols that vanish after correction by supervisors. This approach also opened the laboratory for the public and turned out to be an interesting concept to support collaborations.

In each semester the students' perceptions of all laboratories, including the OPLChem, are evaluated. The evaluation is generally done at the beginning of the $2^{\text {nd }}$ half of the semester. Afterwards the evaluation is discussed with the students and consequences are planned from the results.

The evaluation of the winter semester 2015/16 showed that the OPLChem was judged very positively by the students. The students could rate statements from 1 (very low, strongly disagree) to 5 (very high, strongly agree). Table 1 gives an overview on the most important questions in the evaluation and the average outcome (further details of the survey are found in the Appendix).

Table 1. Most Important Averaged Values of the Students' Answers (N=16) In the Evaluation of the Winter Term 2015/16 (see Appendix).

\begin{tabular}{|l|c|c|}
\hline Question & $\begin{array}{c}\text { Average } \\
(\mathbf{1 ~ . . ~ 5 ) ~}\end{array}$ & Standard Deviation \\
\hline $\begin{array}{l}\text { How big was your interest at the } \\
\text { beginning of the module ? }\end{array}$ & 3.8 & 0.8 \\
\hline The teacher speaks clearly and activating & 4.7 & 0.6 \\
\hline $\begin{array}{l}\text { The teacher can well explain complicated } \\
\text { topics }\end{array}$ & 4.4 & 0.6 \\
\hline The teacher is well prepared & 4.5 & 0.8 \\
\hline The teacher gives regular summaries & 4.1 & 0.8 \\
\hline $\begin{array}{l}\text { My interest for the course has strongly } \\
\text { grown during the semester }\end{array}$ & 3.5 & 1.3 \\
\hline
\end{tabular}




\begin{tabular}{|c|c|c|}
\hline I believe to learn much & 3.4 & 1.2 \\
\hline The teacher gives a good overview & 3.6 & 1.2 \\
\hline I learn much for my later studies & 3.5 & 1.4 \\
\hline $\begin{array}{l}\text { Ho difficult is the course compared to } \\
\text { other courses? }\end{array}$ & 2.0 (quite easy) & 0.8 \\
\hline How do you rate the course all over? & 4.3 & 0.9 \\
\hline $\begin{array}{l}\text { I can trust my competency in difficult } \\
\text { situations }\end{array}$ & 3.7 & 1.1 \\
\hline $\begin{array}{l}\text { I can solve most problems with own } \\
\text { forces }\end{array}$ & 3.7 & 0.9 \\
\hline $\begin{array}{l}\text { I can also solve exhausting and } \\
\text { complicated problems }\end{array}$ & 3.5 & 0.8 \\
\hline $\begin{array}{l}\text { I was well informed about the content of } \\
\text { this course }\end{array}$ & 4.1 & 1.1 \\
\hline $\begin{array}{l}\text { The teacher takes care of a pleasant } \\
\text { learning environment }\end{array}$ & 4.2 & 1.3 \\
\hline The teacher cares about students interests & 4.5 & 1.1 \\
\hline The teacher shows respect and esteem & 4.3 & 1.4 \\
\hline $\begin{array}{l}\text { The teacher trusts into the students } \\
\text { competencies }\end{array}$ & 4.1 & 1.3 \\
\hline $\begin{array}{l}\text { The teacher motivates the students to get } \\
\text { into difficult content }\end{array}$ & 4.0 & 1.1 \\
\hline $\begin{array}{l}\text { The teacher encourages the students in } \\
\text { case of failure }\end{array}$ & 3.9 & 1.3 \\
\hline $\begin{array}{l}\text { The teacher especially supports single } \\
\text { students who need help }\end{array}$ & 3.5 & 1.3 \\
\hline $\begin{array}{l}\text { The teacher gives clear feedback to } \\
\text { students contributions and questions }\end{array}$ & 4.1 & 1.1 \\
\hline $\begin{array}{l}\text { The teacher gives constructive feedback } \\
\text { to students contributions and questions }\end{array}$ & 4.3 & 1.0 \\
\hline $\begin{array}{l}\text { The teacher achieves that most students } \\
\text { get actively involved }\end{array}$ & 3.7 & 1.0 \\
\hline $\begin{array}{l}\text { The teacher motivates to get engaged into } \\
\text { the course at home }\end{array}$ & 3.9 & 1.1 \\
\hline $\begin{array}{l}\text { The teacher opens the possibility to get } \\
\text { deeper into interesting topics }\end{array}$ & 4.4 & 0.7 \\
\hline The atmosphere in the group was pleasant & 4.5 & 0.6 \\
\hline $\begin{array}{l}\text { The quality of the other students projects } \\
\text { is very good }\end{array}$ & 4.1 & 0.8 \\
\hline $\begin{array}{l}\text { The collaboration with other students } \\
\text { works out very good }\end{array}$ & 4.3 & 0.8 \\
\hline $\begin{array}{l}\text { I had wished more influence of the } \\
\text { teacher on my project }\end{array}$ & 2.4 & 0.7 \\
\hline $\begin{array}{l}\text { I had wished less influence of the teacher } \\
\text { on my project }\end{array}$ & 2.0 & 1.1 \\
\hline $\begin{array}{l}\text { I have learned something from other } \\
\text { members of my group }\end{array}$ & 3.5 & 0.9 \\
\hline $\begin{array}{l}\text { The media used helped me to follow the } \\
\text { course }\end{array}$ & 4.0 & 0.8 \\
\hline $\begin{array}{l}\text { The offered materials help to understand } \\
\text { the course content }\end{array}$ & 3.8 & 0.9 \\
\hline $\begin{array}{l}\text { White board drawings, slides and } \\
\text { presentations are understandable }\end{array}$ & 4.1 & 0.7 \\
\hline
\end{tabular}


All over $81.3 \%$ of the students (13) would recommend the course to other students, 2 students $(12.5 \%)$ do not know and 1 student $(6.3 \%)$ would not do so. 16 students participated in the survey.

The students positively evaluated the variety of materials that was offered on the Moodle platform. The videos, instructive figures, tables and presentations were approved by more than $75 \%$ of the students. Interestingly, only $62.5 \%$ judged the experiments, which should be the core of the OPLChem, as helpful. This value even dropped in the evaluation 2016/17 where only $45.5 \%$ of all students judged the experiments helpful.

In $2015 / 16$ concrete examples were judged to be less helpful (37.5\%). This is a strong contrast to modules that are not research-based (like mathematics for chemists) where the students ask for more concrete examples quite often. However this figure seems to vary strongly as $63.6 \%$ of all students judged the concrete examples as helpful in 2016/17.

Generally, the implementation of various media to follow the course was judged as helpful $(4.0,1.0=$ not at all helpful, $5.0=$ very helpful $)$. All other evaluation results, which are not especially pointed out for the winter semester $2016 / 17$, remained rather unchanged so that the general evaluation result can be judged as constant.

Interviews with the students showed that especially the groups who had experience with RBL during their school time were quick in finding project ideas or even wanted to proceed with their former school projects. Other students worried later that the large number of possibilities and ideas was not known at the beginning of the semester. This fact possibly contributed to the result that some students judged their interest to be strongly growing during the time of the OPLChem studies.

The students from MINT ${ }^{\text {grün }}$ judged the requirements of the OPLChem as slightly higher than average, while the students of the Bachelor in Chemistry judged them lower.

The students finally accepted the RBL concept of the OPLChem and especially praised the option to choose their own topics and the individual support by teachers. The students were also happy to be able to experience research work in an early phase of their studies. They perceived the work in the laboratory as real research.

The OPLChem course takes 4-8 hours of weekly presence including the fixed workshop ( 2 hours weekly) for presentations, feedback, and discussions of the experiments, as well as lectures given by the instructors for selected topics covering best practice examples, safety instructions, scientific working, scientific writing, literature research, video production and an introduction into Wordpress ${ }^{\circledR}$. So 2-6 hours (from these 4-8 hours) weekly are used for the laboratory work. The efforts strongly varied between different groups as some conducted well-defined experiments with small efforts, while others tried different approaches in the laboratory and still finished a complicated program defined by trial and error. In addition to the presence time, the students perform about 30-40 hours for the watching of online videos, literature research, preparation of their experiments, and evaluation of data (see Appendix). However more than $40 \%$ of the students 
seem to be involved only little in such homework as they answered that they spend between 0-2 hours per week next to their presence time. A similar fraction spends 2-4 hours weekly while only 2 of 16 students who answered the evaluation invested more than 4 hours per week. As the time for finishing protocols, online materials and presentations follows the evaluation this effort is not yet included. About 10-20 hours have to be spent on video production, 10-20 hours for the preparation of the presentations, and another 10-20 hours for the establishment of the blogs. The protocol is also assumed to take another 10-20 hours. All these elements are hardly under control and surely do not involve all students as some students complained that a large fraction of the documentation of the group's efforts was undertaken by only a few selected students.

Some students from the group of Bachelor in Chemistry students complained that they invested more than the $180 \mathrm{~h}$ working time as suggested by 6 ECTS credits. This value can be easily reached if a group is engaged in a laboratory time of up to 8 hours/week (the semester usually ranges over 14 weeks), and an exhaustive preparation of students' own experiments, including complete documentation and video production on a nice blog, is established. That might take up more than the presence time and finally could end up with up to 300 hours as indicated by one group.

However, the opposite was also observed. There might be a minimum time students spend in a large group if keeping in the background all time. On the other hand, most of the groups asked during interviews indicated that the workload was equally distributed.

It is suggested to target this topic clearly at the beginning of the semester and to demand a defined time of presence of about 8 hours/week and a clear spread of the issues of one project among all members of the group. The contribution of all group members for the preparation of the outcomes can be registered.

Also between different groups strong differences were observed. Some groups finished their experiments with 12 pages of a rather quickly written protocol that did not go into deep detail, while other groups presented an elaborated work of 70 pages in a well-written style together with clear conclusions.

\section{Conclusions}

The main aim of the OPLChem is to show the students how situations of real laboratory research look. The experience of experimental failures is a precious and usual experience for real researchers. Some students are motivated to get involved into hard working engagement to solve difficult issues in chemistry. This might sound like a contradiction to motivation; however, we believe that RBL leads to strong motivation to conduct rather large workloads at least for some students. RBL is highly appreciated by the students. Flexibility in scheduling the time for the experiments was positively judged in particular.

However, it seems as RBL works better for students who are quite successful in their studies, while some students tried to avoid the strong engagement into the 
projects and used the flexible structure of the RBL concept in OPLChem to reduce their efforts.

Therefore, we started to define the distribution of the workload between the students during the introduction period. It needs to be part of the concept the students have to present before starting the experiments in their projects.

As one part, a protocol template was developed to be used in the summer semester 2017 for the first time. The template structures the written work similar to a scientific publication and should therefore lead to protocols that are more easily comparable between different groups. This idea might contradict the principal concepts of RBL (Huber, 2013), however we believe that it is suitable to raise the output and engagement of all students and improve the quality of the projects without losing the RBL character.

Generally, online videos together with online pre-examinations have positive effects on the students' learning progress. Students were much better enabled to start over with experiments right from the beginning. The number of basic questions asked by the students who prepared themselves with online videos clearly reduced. The students were much more professional in handling setups, samples, and chemicals. Also the quality of the students' protocols rose significantly if they studied online videos in comparison to students who did not do so. All over fewer efforts were necessary to supervise the students. Thus the working time in the laboratory was used more efficiently, and a larger number of students could be supervised.

We believe that the concept of RBL in orientation studies together with blended learning elements like online videos and blogs, which are produced as parts of the protocols by the students themselves, is highly attractive. RBL brings students in contact with the requirements of the subjects on one side and gives them freedom to follow their own research questions on the other side. It allows good students to explore their limits. As a part of a curriculum, next to the large number of clearly structured modules covering the teaching matter from mathematics to physical, technical, analytical and organic chemistry, RBL-based modules are a compensating element motivating the students to overcome basic demands and end up as researchers. RBL should include elements that are typical for the subject, for example the need to write elaborated and exact protocols, as they are part of studies in chemistry. This ensures that students in MINT grün experience the study reality and get a good orientation from participating in OPLChem. However, RBL should also allow for the freedom of a researcher to choose his questions, to design experiments, and to schedule time on his own.

The blended learning elements are part of a strategy that enables the students to incorporate technical skills into their studies such as the ability to produce good videos or blogs. Additionally, this approach produces a growing pool of materials that is visible from outside the university and therefore advertises the students' results to the public.

In a follow up project called SynTUBio we want to transfer this concept of teaching, covering the broad view from basic teaching content (like mathematics) or applications in practical courses (mainly in physical chemistry, organic chemistry and synthetic biology) to research during the $\mathrm{PhD}$ or during laboratory 
work as a scientist who is employed in a research department of a company. We believe that such approaches are also highly relevant for orientation studies to allow students not only to experience the different approaches of the different graduation programs, but also the reality they are facing after graduation. This enables them to judge early if such working conditions are compatible with their expectations.

\section{Acknowledgments}

The authors acknowledge support by TU Berlin in the framework of the study reform project educationZEN in practical courses. Special thanks belongs to the Board of Teaching and Study (LSK) and the board of the faculty (Faculty II Mathematics and Natural Sciences of TU Berlin) who were both engaged in discussions and contributed with constructive criticism to the success of this project and finally decided on the funding in a positive way. Thomas Friedrich and Franz-Josef Schmitt especially thank the Stifterverband für die Deutsche Wissenschaft and Joachim Herz Stiftung for supporting the projects "OnlineProjektlabor Chemie im Alltag" und "IGT-educationTUB". We acknowledge support by the German Ministry of Education and Research (BMBF) for financing the WIMI $I^{\text {plus }}$ project line at TU Berlin and especially our project SynTUBio. The Central Institute of Scientific Education and Cooperations (ZEWK) at TU Berlin is acknowledged for supervising WIMI $I^{\text {plus }}$. The authors thank Ahmad Aljanazrah from Bierzeit University Palestine for his support and didactic advises.

\section{References}

Ally, M. (2004). Foundations of educational theory for online learning. Theory and practice of online learning, 1-31. Athabasca University.

Baker, J. W. (2000). The "Classroom Flip": Using web course management tools to become the guide by the side. Selected papers from the 11th International Conference on College Teaching and Learning, (pp. 9-17). Jacksonville, FL: Florida Community College at Jacksonville.

Berrett, D. (2012). How 'flipping' the classroom can improve the traditional lecture. The chronicle of higher education.

Bishop, J. L., \& Verleger, M. A. (2013). The flipped classroom: A survey of the research. In ASEE National Conference Proceedings, Atlanta, GA.

Bergmann, J., \& Sams, A. (2012). Flip your classroom: Reach every student in every class every day. International Society for Technology in Education.

Bonk, C. J., \& Graham, C. R. (2006). The handbook of blended learning: global perspectives, local design. Pfeiffer.

Born, S. (2015). A mathematical lab for first year students - Learning by research. Proceedings of the 43rd Annual SEFI Conference June 29 -July 2, 2015 Orléans, France

Fulton, K. (2012). Upside down and inside out: Flip Your Classroom to Improve Student Learning. Learning \& Leading with Technology, 39(8), 12-17.

Garrison, D. R., \& Vaughan, N. D. (2008). Blended learning in higher education: 
Framework, principles, and guidelines. San Francisco: Jossey-Bass.

Holmes, M. R., Tracy, E. M., Painter, L. L., Oestreich, T., \& Park, H. (2015). Moving from flipcharts to the flipped classroom: Using technolo-gy-driven teaching methods to promote active learning in foundation and advanced master's social work courses. Clinical Social Work Journal, 43, 215-224.

Huber, L. (2013). Why researched based learning is necessary and possible, Re-searched based learning during the study. Actual concepts and experiences, 9-35. Bielefeld: Universitäts-Verlag Webler.

Hudson, R., \& Luska, K. L. (2013). Recording tutorials to increase student use and incorporating demonstrations to engage live participants. J. Chem. Educ., 90(5), 527530

Ifenthaler, D., \& Gosper, M. (2014). Research-based learning: connecting research and instruction. Curriculum Models for the 21st Century, 73-89. New York: Springer.

Linga, P., \& Wang, C.-H. (2014). Flipped class learning in a large class set-ting. CDTL Brief, 17(1), 4-9. Retrieved from https://nus.edu/2k3XpoT.

Love, B., Hodge, A., Grandgenett, N., \& Swifta, A. W. (2014). Student learning and perceptions in a flipped linear algebra course. International Journal of Mathematical Education in Science and Technology, 45(3), 317-324

Olapiriyakul, K., \& Scher, J. M. (2006). A guide to establishing hybrid learning courses: Employing information technology to create a new learning experience, and a case study. The Internet and Higher Education, 9(4), 287-301.

Prashar, A. (2015). Assessing the flipped classroom in operations management: a pilot study. Journal of Education for Business, 90, 126-138. Retrieved from http://bit.ly/ $2 \mathrm{kr} 8 \mathrm{owj}$.

Rademacher, L., \& Schröder C. (2015). "Creativity + Construction" as part of the orientation program MINTgrün. Proceedings of the $43^{\text {rd }}$ Annual SEFI Conference June 29 -July 2, 2015 Orléans, France.

Raue, C., \& Schröder, C. (2014). Das Orientierungsstudium MINT ${ }^{\text {grün. }}$ flankierter Systemübertritt von Schule zu Hochschule [Orientation Study Program MIN ${ }^{\text {grün: }}$ Supporting the system transition from school to university]. Zeitschrift für Hochschulentwicklung, 9(5), 179-199.

Schmitt, F.J., Schönnemann, T., Kruse, F., Egbers, F., Delitzscher, S., Weißenborn, J., Aljanazrah, A., \& Friedrich, T. (2015). Targeted inversion of the tutorials in "Mathematics for Chemists", a case study. Proceedings of the Global Learn, April 2015. Association for the Advancement of Computing in Education (AACE).

Schmitt, F.J., Schröder, C., Campbell, Z.Y., Wilkening S., Moldenhauer M., \& Friedrich, T. (2017a). Self-dependent students in transdisciplinary projects tend to higher interest in sustainability research, Education Excellence for Sustainable Development, SEFI Annual Conference 2017, Azores Islands, Portugal. Retrieved from http://bit.ly/2zUTUaR.

Schmitt, F. J., Kruse, F., Egbers, F., Delitzscher, S., Schönnemann T., Theis, B., Wilkening, S., Moldenhauer, M., Wiehe, R., Willoweit, M., Keuer C., Aljanazrah, A., \& Friedrich, T. (2017b). Effectiveness of Using Interactive Targeted Inverted (IGT)-Education on Students' Learning at the Technische Universität Berlin. Proceedings of the Society for Information Technology \& Teacher Education International Conference, Austin, TX, Association for the Advancement of Computing in Education (AACE)

Schultz, D., Duffield, S., Rasmussen, S.C., \& Wagemann, J. (2014). Effects of the flipped classroom model on student performance for advanced placement high school chemistry students. J. Chem. Educ., 91(9), 1334-1339.

Tucker, B. (2012). The flipped classroom. Education Next, 12(1), 82-83. 


\section{Appendix}

Evaluation results of the OPLChem in the winter term 2015/16

\section{Auswertungsteil der geschlossenen Fragen}

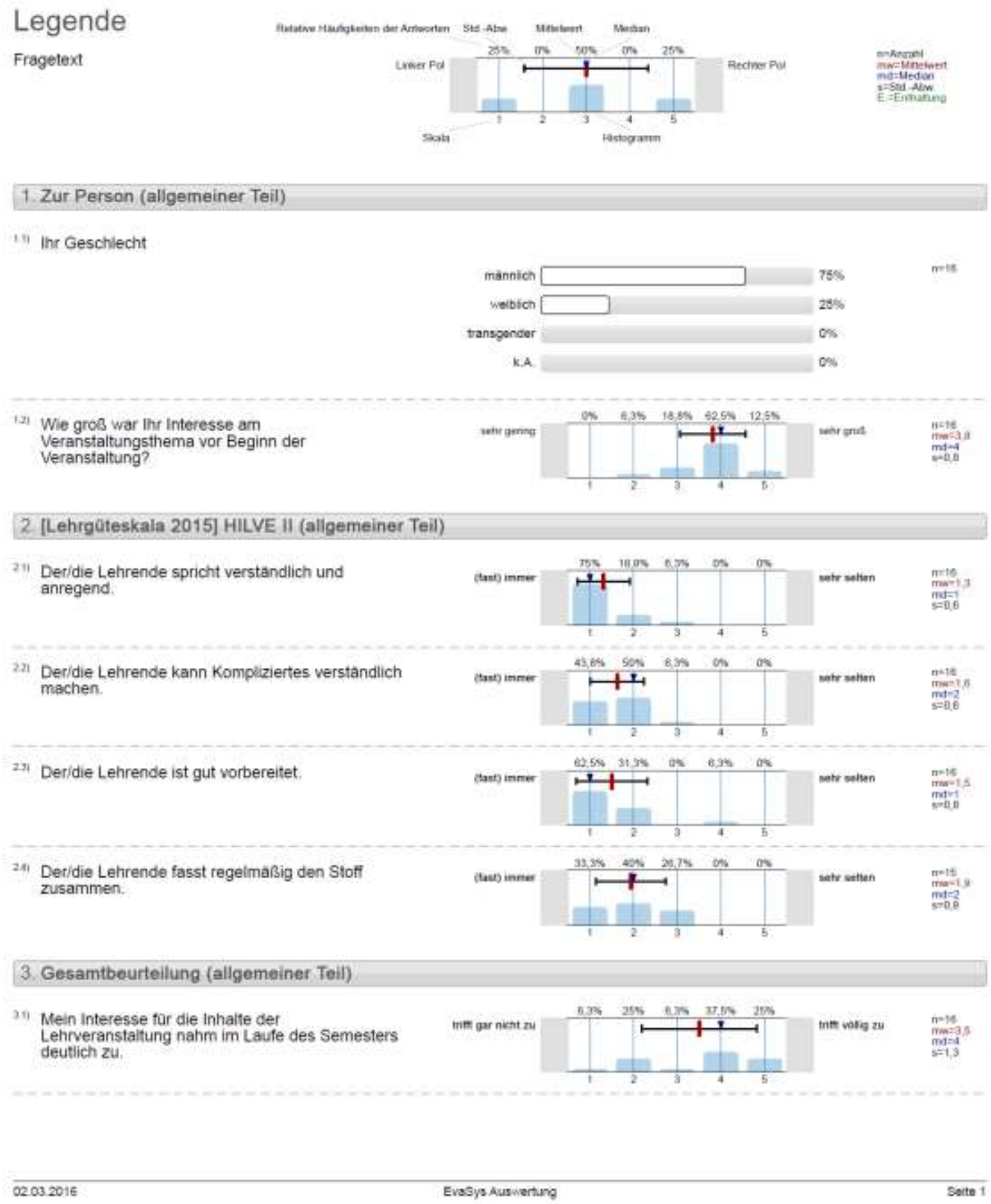


Vol. 5, No. 4 Schmitt et al.: Student-Centred Teaching in Laboratories Supported...

I2y Ich denke, dass ich in dieser Lehrveranstaltung viel leme.
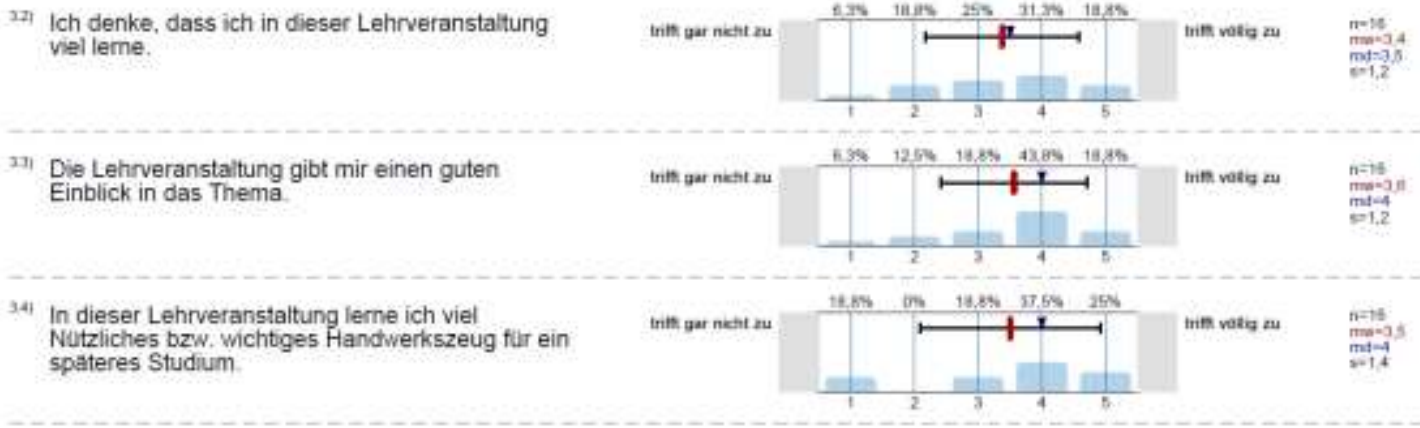

39. Wie viele Stunden investieren Sie ungefahr fur die Vor- und Nachbereitung dieser Veranstaltung pro Woche?

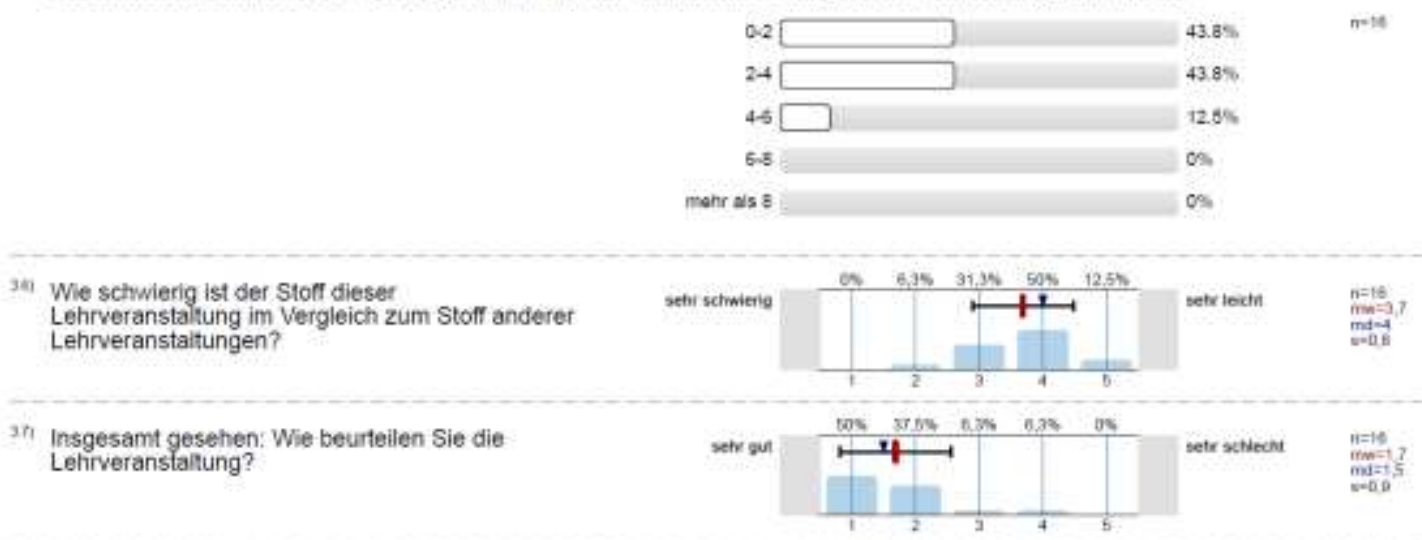

32 Wurden Sie diese Lehrveranstaltung anderen Studierenden empfehlen?

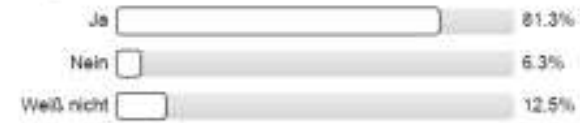

4. Allgemeine Selbstwirksamkeit Kurzsskala (ASKU) (Labore)

47. In schwierigen Situationen kann ich mich auf meine eigenen Făhigkeiten veriassen.

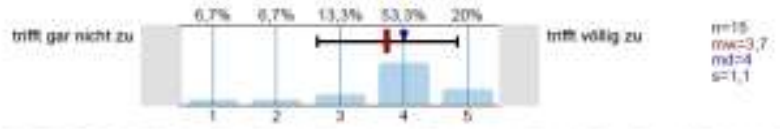

42i Die meisten Probleme kann ich aus eigener Kraft gut meistern.

trits gar nicht zu

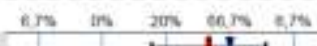

thit watig an

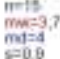

3i Auch anstrengende und komplizierte Aufgaben kann ich in der Regel gut lósen.

trith gar nicht wo

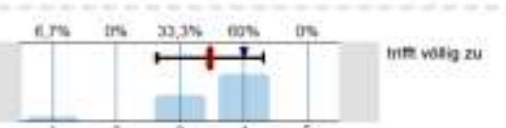

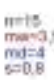

5. Bitte beurteilen Sie die folgenden Aussagen zu diesem Projektlabor.

511 Ich wurde vor der Entscheidung fur dieses Projektlabor ausreichend uber die Inhalte informiert.

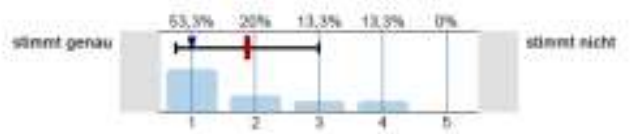


6. [LeKo] Gute Lernatmosphăre herstellen (Labore)

411 Deridie Lehrende sorgt fur eine angenehme Lematmosphare

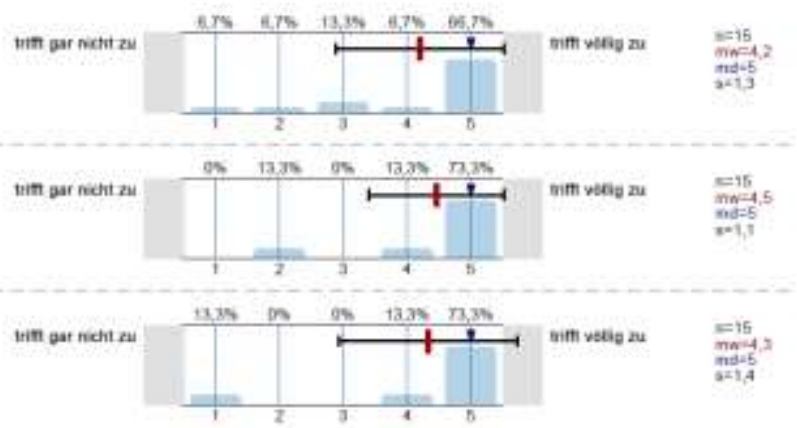

7. [LeKo] Ermutigen \& Selbstwirksamkeit starken (Labore)

11i Deridie Lehrende vermittelt grundlegendes Vertraven in die Fahigkeit der Studierenden.

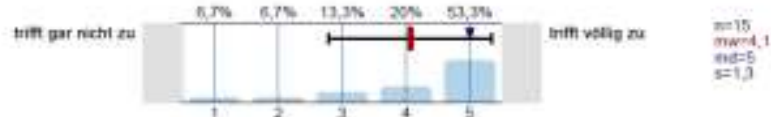

72. Deridie Lehrende ermutigt die Studierenden bei der Aneignung schwieriger Inhalte

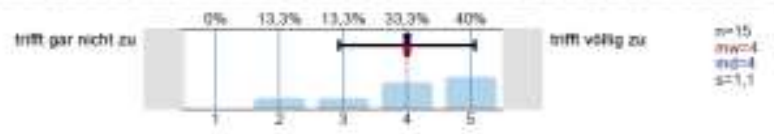

73i Der/die Lehrende starkt Studierende bei Misserfoig im Lernprozess.

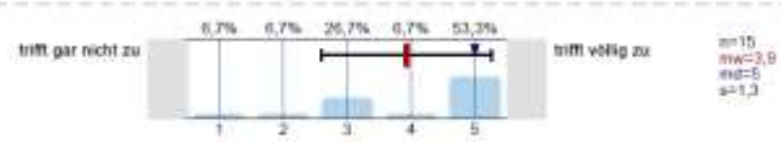

74) Deridie Lehrende unterstutzt gezielt einzelne Studierende oder Studierendengruppen, die einen besonderen Unterstutzungsbedarf haben.

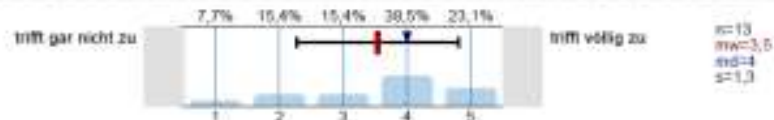

\section{8. [LeKo] Lerndienliches Feedback geben (Labore)}

all Deridie Lehrende gibt aussagekraftiges Feedback auf die Beitrage/Antworten der Studierenden.

tim gar neth nu

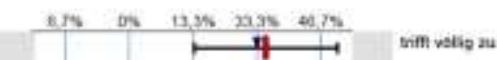

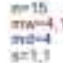

s7) Deridie Lehrende gibt konstruktives Feedback aut die Beitrage/Antworten der Studierenden.

tum gar nath nu

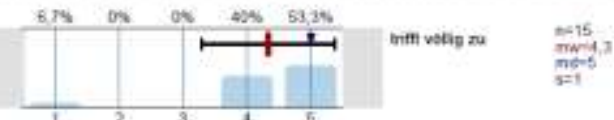

9. [LoKo] Zur Selbstständigkeit anregen (Labore)

97 Deridie Lehrende erreicht, dass sich die meisten Studierenden aktiv an der Lehrveranstaltung beteiligen

tin gat nechtsu

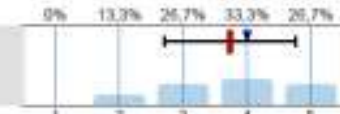

gim votag an

321 Deridie Lehrende regt die Studierenden an. sich mit den Lehrinhalten auch aulberhalb der veranstaltung auseinanderzusetzen 

D37. Deridie Lehrende eroffinet den Studierenden
Móglichkeiten, sich mit interessanten Inhaiten eingehender zu beschastigen

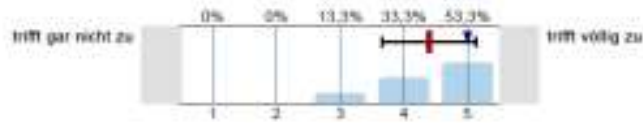

10. Mitlernende (alter FB + Biwi-Projekt, Einzelitems) (Labore)

"1" Die Arbeitsatmosphare ist innerhalb der Projektgruppe sehr angenehm.

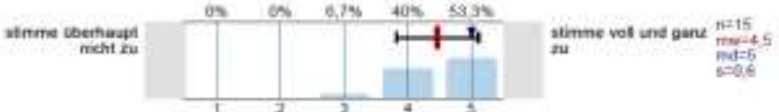

${ }^{104}$ Die Qualitat der Projektbeitrage meiner Mitstudierenden ist sehr gut

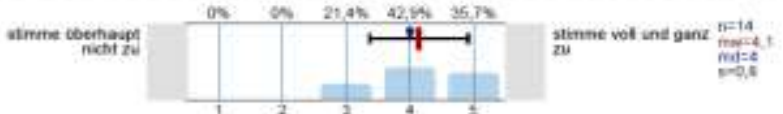
10.7 Die Zusammenarbeit mit meinen Mitstudierenden
funktioniert sehr gut.
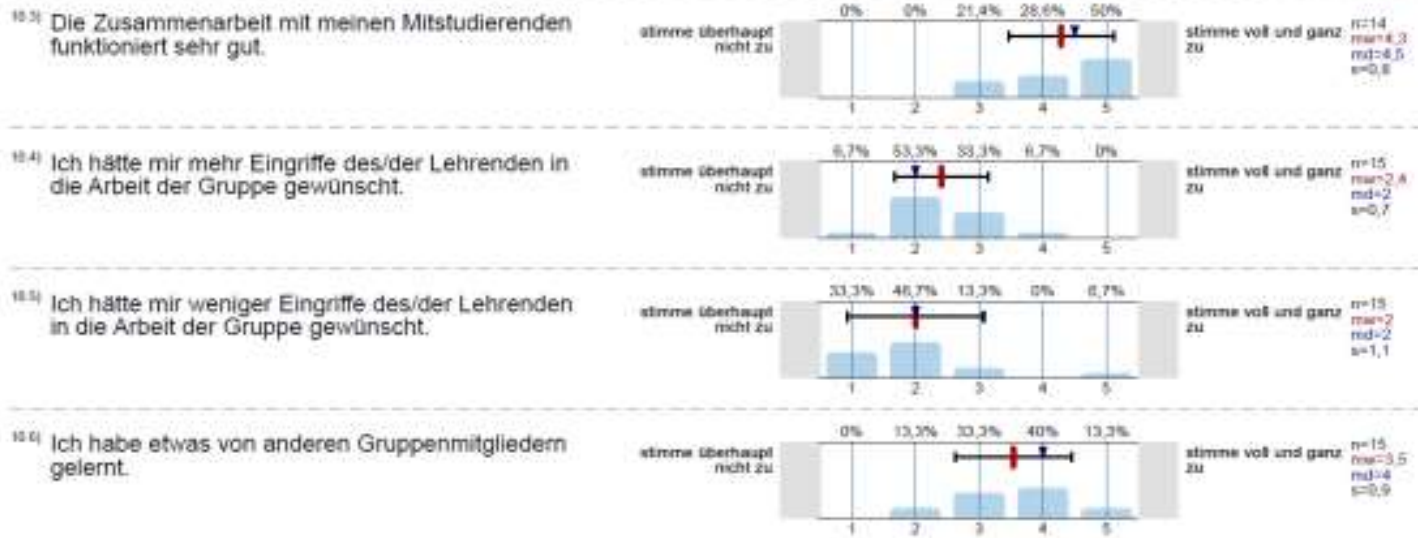

\section{Medieneinsatz (alter FB) (Labore)}

1:t1 Die Lehrveranstaltung wird durch unterschiedliche Vermittlungsformen unterstutzt: (Mehrfachantworten möglich .)

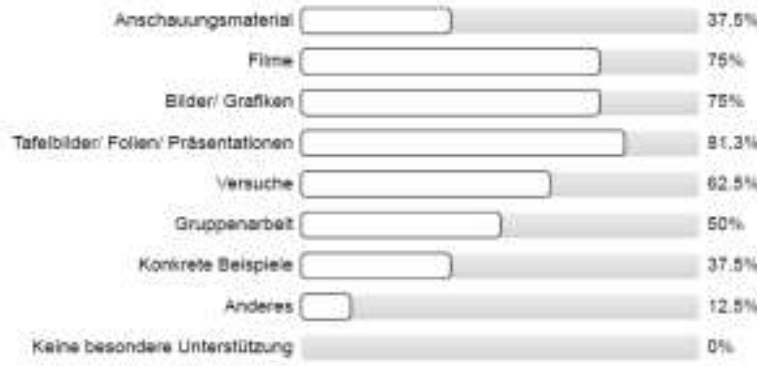

114 Der gezielte Medieneinsatz hilf mir, der
Lehrveranstaltung zu folgen.

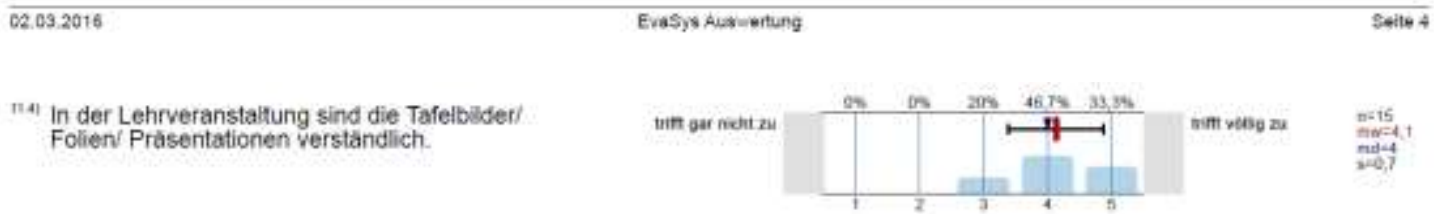

